\title{
A global view of porcine transcriptome in three tissues from a full-sib pair with extreme phenotypes in growth and fat deposition by paired-end RNA sequencing
}

Congying Chen, Huashui Ai, Jun Ren, Wanbo Li, Pinghua Li, Ruimin Qiao, Jing Ouyang, Ming Yang, Junwu Ma and Lusheng Huang*

\begin{abstract}
Background: Elucidation of the pig transcriptome is essential for interpreting functional elements of the genome and understanding the genetic architecture of complex traits such as fat deposition, metabolism and growth.

Results: Here we used massive parallel high-throughput RNA sequencing to generate a high-resolution map of the porcine mRNA and miRNA transcriptome in liver, longissimus dorsi and abdominal fat from two full-sib $F_{2}$ hybrid pigs with segregated phenotypes on growth, blood physiological and biochemical parameters, and fat deposition. We obtained 8,508,418-10,219,332 uniquely mapped reads that covered $78.0 \%$ of the current annotated transcripts and identified 48,045-122,931 novel transcript fragments, which constituted 17,085-29,499 novel transcriptional active regions in six tested samples. We found that about $18.8 \%$ of the annotated genes showed alternative splicing patterns, and alternative $3^{\prime}$ splicing is the most common type of alternative splicing events in pigs. Crosstissue comparison revealed that many transcriptional events are tissue-differential and related to important biological functions in their corresponding tissues. We also detected a total of 164 potential novel miRNAs, most of which were tissue-specifically identified. Integrated analysis of genome-wide association study and differential gene expression revealed interesting candidate genes for complex traits, such as IGF2, CYPIA1, CKM and CES1 for heart weight, hemoglobin, pork pH value and serum cholesterol, respectively.
\end{abstract}

Conclusions: This study provides a global view of the complexity of the pig transcriptome, and gives an extensive new knowledge about alternative splicing, gene boundaries and miRNAs in pigs. Integrated analysis of genome wide association study and differential gene expression allows us to find important candidate genes for porcine complex traits.

Keywords: novel transcript unit, alternative splicing, gene boundary, miRNA, differentially expressed gene, complex trait, pig

\section{Background}

The pig has been providing with large scale products for human consumption. It also services as an important animal model for human diseases including obesity, diabetes, cardiovascular disease and endocrinology because of the similarity in physiology, organ development and

\footnotetext{
* Correspondence: Lushenghuang@hotmail.com Key Laboratory for Animal Biotechnology of Jiangxi Province and the Ministry of Agriculture of China, Jiangxi Agricultural University, 330045, Nanchang, China
}

(c) 2011 Chen et al; licensee BioMed Central Ltd. This is an Open Access article distributed under the terms of the Creative Commons Attribution License (http://creativecommons.org/licenses/by/2.0), which permits unrestricted use, distribution, and reproduction in any medium, provided the original work is properly cited. disease progression [1]. However, until now, only several causative mutations have been isolated for porcine complex traits, e.g. IGF2 for muscle growth and fat deposit [2], PRKAG3 for glycogen content in skeletal muscle [3] and NR6A1 for number of vertebrae [4]. Elucidating the complexity of the pig transcriptome is not only essential for interpreting the functional elements of the genome, but also benefits the understanding of human related complex traits such as fat deposition, metabolism and growth. For example, UTR lengths are correlated with 
gene function, localization and requirements for regulation [5]; alternative splicing plays a major part in biological complexity in humans [6]; and non-coding RNAs (ncRNA) are crucial for multiple biological processes $[7,8]$.

The global transcriptome profilings in abdominal fat, induced fat cells, muscle, liver and pituitary gland have been investigated in pigs by long SAGE analysis, fulllength enriched cDNA library and microarray [9-11]. However, the complexity of the porcine transcriptome is not yet fully elucidated. The massively parallel sequencing using next generation sequencer (RNA-seq) provides a huge potential to revolutionize the field of pig transcriptome, owning to its abilities to discover extensive alternative splicing and identify large-scale novel transcripts at single-nucleotide resolution [12-15]. Moreover, the paired-end sequencing strategy of RNA-seq further improves sequencing efficiency and extends short read lengths for better understanding transcriptome [16]. RNA-seq has opened a new horizon for our understanding of global gene expression and has demonstrated the complexity of mammalian transcriptome vastly underestimated before.

MiRNAs are a class of small RNAs that regulate gene expression by decreasing the target mRNA levels or inhibiting translation of protein encoding transcripts. Global miRNA abundance has been measured in skeletal muscle by microarray to evaluate the roles of miRNAs in pig development and meat production [17-19]. MiRBase 15.0 database has collected 189 porcine mature miRNAs. RNA-seq also provides valuable insights into miRNA transcriptome, especially into those miRNAs insufficiently detected by microarray. Until now, porcine miRNA transcriptome has been investigated by next generation sequencer in intestine [20], pre- and postnatal piglet [21], developing brain [22] and skeletal muscle [23].

We herein performed a global transcriptome analysis on three types of tissues related to metabolism, meat production and fat deposition: liver, longissimus dorsi muscle (LD) and abdominal fat (AF) harvested from a full-sib $\mathrm{F}_{2}$ female pair with extreme phenotypes by RNA-seq. The results allowed us to investigate largescale alternative splicing events, identify extensive number of novel transcript units, determine gene boundaries at single nucleotide resolution and comprehensively survey porcine microRNAs in the tested tissues. To our knowledge, this study presented the first systematical investigation on the complexity of porcine transcriptome with nucleotide resolution. Moreover, this study identified many important candidate genes related to growth, meat quality, blood physiological and biochemical parameters by the integrated analysis of genome-wide association study and differential gene expression.

\section{Results}

Sequencing and mapping of the porcine transcriptome

We sequenced cDNA libraries from 3 tissues of the fullsib female pair using High-seq 2000 at BGI-Shenzhen, China. The data set was analyzed according to the BGI bioinformatics protocols for RNA-seq. The sequence reads have been submitted to the NCBI Gene Expression Omnibus under accession no. GSE26572. In total, we acquired 38,808,956-40,133,362 paired-end reads of 90 bp. The total read length was 21.3 gigabases $(\mathrm{Gb})$, representing about 8 -fold of the porcine genome size. We technically replicated the RNA-Seq experiments in the 6 samples with $0.90<R^{2}<0.93$ (Additional file 1). Furthermore, the expression patterns of 16 randomly selected transcripts between two individuals were validated by qRT-PCR with a relative coefficient of $R^{2}=0.8$ (Additional file 1). The technical replicates and qRT-PCR confirmed the high reproducibility of RNA-seq in this study.

We aligned all short reads onto the whole reference genome (Sscrofa9.2). Tolerances were set to allow at most two mismatches for $90 \mathrm{bp}$ reads in each alignment. About $61.4-65.6 \%$ of reads were mapped to the pig reference genome, of which $60.2-74.9 \%$ fell in annotated exons; $24.1-38.3 \%$ located in introns; $0.04-0.06 \%$ overlapped with exons, and the remaining $0.8-1.4 \%$ were assigned to intergenic regions (Sscrofa9.2). Total 53.1$60.8 \%$ of reads had a uniquely genomic location, and 47.9-63.1\% of reads corresponded to reference genes with $21.3-25.5 \%$ of uniquely matched reads. Unmapped or multi-position matched reads (39.2-46.9\%) were excluded from further analyses (Table 1).

\section{Identification of an extensive number of novel transcript units}

The uniquely mapped reads $(8,508,418-10,219,332)$ covered $78.0 \%(21,414 / 27,444)$ of the annotated transcripts in UCSC pig genome database [24] by at least one sequence read. A total of 15,776 transcripts were expressed in all three tissues, and 266, 175 and 2,154 transcripts were discovered exclusively in AF, LD and liver, respectively (Figure 1). We quantified the gene expression level by counting the number of reads per kilobase per million mapped reads (RPKM). About 74.6$84.3 \%$ of the annotated transcripts showed expression with > 0.5 RPKM. The obtained transcription fragments of more than $99.9 \%$ of the detected transcripts were > $150 \mathrm{bp}$ in length (Additional file 2). The percentage of a gene covered by reads was defined as gene coverage. Extensive read mapping revealed about $40.3-50.9 \%$ of the detected transcripts with more than $50.0 \%$ in gene coverage.

We detected an extensive number of novel transcript units by the procedures described in Methods and Zhang et al. (2010) [25]. In total, we obtained 122,931, 
Table 1 Summary of the numbers of reads, identified genes, novel transcribed units, alternative splicing genes and extended genes

\begin{tabular}{ccccccc}
\hline & $\mathbf{2 2 6 8} \mathbf{A F}$ & $\mathbf{2 2 6 8}$ liver & $\mathbf{2 2 6 8}$ LD & $\mathbf{2 2 7 0} \mathbf{A F}$ & $\mathbf{2 2 7 0}$ liver & $\mathbf{2 2 7 0}$ LD \\
\hline total reads & $40,000,000$ & $38,808,956$ & $39,020,950$ & $40,000,000$ & $40,133,362$ & $39,164,798$ \\
total unmapped reads & $14,293,709$ & $13,771,813$ & $14,076,474$ & $15,445,291$ & $14,285,367$ & $13,457,962$ \\
reads perfectly matched to the reference genome & $16,867,579$ & $17,398,322$ & $12,737,195$ & $15,882,824$ & $17,575,361$ & $13,920,553$ \\
reads with $<$ 2 bp mismatch to the reference genome & $8,838,712$ & $7,638,821$ & $12,207,281$ & $8,671,885$ & $8,272,634$ & $11,786,283$ \\
reads uniquely matched to the reference genome & $22,908,741$ & $22,998,328$ & $23,301,854$ & $21,235,855$ & $23,695,323$ & $23,823,564$ \\
reads matched to the reference genome with multi-positions & $2,797,550$ & $2,038,815$ & $1,642,622$ & $3,318,854$ & $2,152,672$ & $1,883,272$ \\
annotated genes identified in this study & 19,062 & 17,382 & 15,612 & 18,695 & 17,447 & 15,716 \\
reads uniquely matched to annotated genes & $8,508,418$ & $9,465,873$ & $8,615,406$ & $9,075,466$ & $10,219,332$ & $9,530,691$ \\
reads matched to annotated genes with multi-positions & $10,648,618$ & $15,009,898$ & $13,906,877$ & $10,839,003$ & $15,072,157$ & $13,441,905$ \\
novel transcript units & 122,931 & 71,394 & 48,045 & 112,052 & 72,401 & 69,677 \\
clustered transcriptionally active regions & 29,499 & 22,871 & 17,085 & 25,842 & 21,840 & 22,099 \\
alternative splicing genes & 2882 & 1,851 & 1,859 & 2,832 & 2,116 & 1,657 \\
5' extended genes & 815 & 610 & 587 & 793 & 697 & 593 \\
3' extended genes & 1,201 & 1,375 & 1,075 & 1,360 & 1,224 & 1,064 \\
Genes extended both 5' and 3' ends & 672 & 551 & 432 & 636 & 590 \\
\hline
\end{tabular}

$71,394,48,045,112,052,72,401$ and 69,677 novel transcript units, respectively, in the six tested samples with a mean length of $285 \mathrm{bp}$ and a size range from 150 to 39,638 bp (Table 1). Many novel transcript units (27.7$85.1 \%$ ) have $>1$ exons and the largest one is $39,638 \mathrm{bp}$ in length containing 136 exons (Additional file 3). The novel transcript units were often identified in clusters, indicating that closely spaced transcript units are likely to merge into longer transcripts with increasing sequencing depth. By scanning the genomic location of each novel transcribed unit, we clustered adjacent fragments $( \pm 3 \mathrm{~kb})$ into one transcriptionally active region. In this

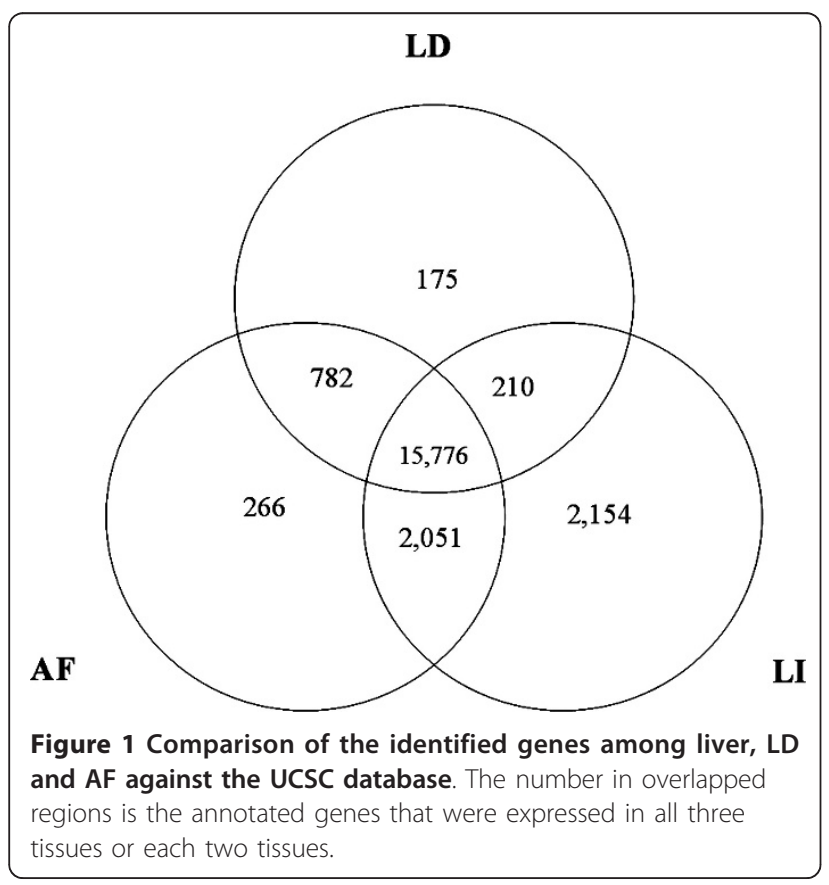

way, we identified 17,085-29,499 novel transcriptionally active regions in the six tested samples (Table 1). A proportion (3.6-16.9\%) of the regions was comprised of single exon.

To investigate whether the identified novel transcript units were non-coding RNAs, we aligned the sequences of the novel transcript units to non-coding RNA precursor sequences in Rfam database [26]. We found that $0.12-0.17 \%$ of novel transcript units were non-coding RNA precursors. Of these, $47.0 \%$ were in average tRNA precursors, $26.2 \%$ were miRNA precursors and $15.6 \%$ were snoRNA precursors.

\section{Alternative splicing events in pig transcriptome}

To investigate alternative splicing, we identified the sequence reads that were mapped to the regions of computationally determined theoretical splicing junctions. Four known types of alternative splicing models including alternative 3' splicing site, alternative 5' splicing site, exon skipping and intron retention were considered in this study. The distribution of alternative splicing events is shown in Additional file 4. The alternative splicing events from 3 tissues of one individual were pooled and the redundancy was removed to get a final set of alternative splicing events. We found that up to 4,038 genes accounting for $18.9 \%$ of the known genes had undergone alternative splicing in these tissues, displaying 10,746 alternative events in individual 2268. Similarly, the number of alternative splicing genes and events in individual 2270 were 4,024 (18.8\% of the known genes) and 10,854, respectively (Table 1 and Additional file 5). Figure $2 \mathrm{~A}$ and $2 \mathrm{~B}$ show an example of intron retention and alternative 5 ' splicing site. We found that about $59.0 \%$ of the alternative spliced genes 


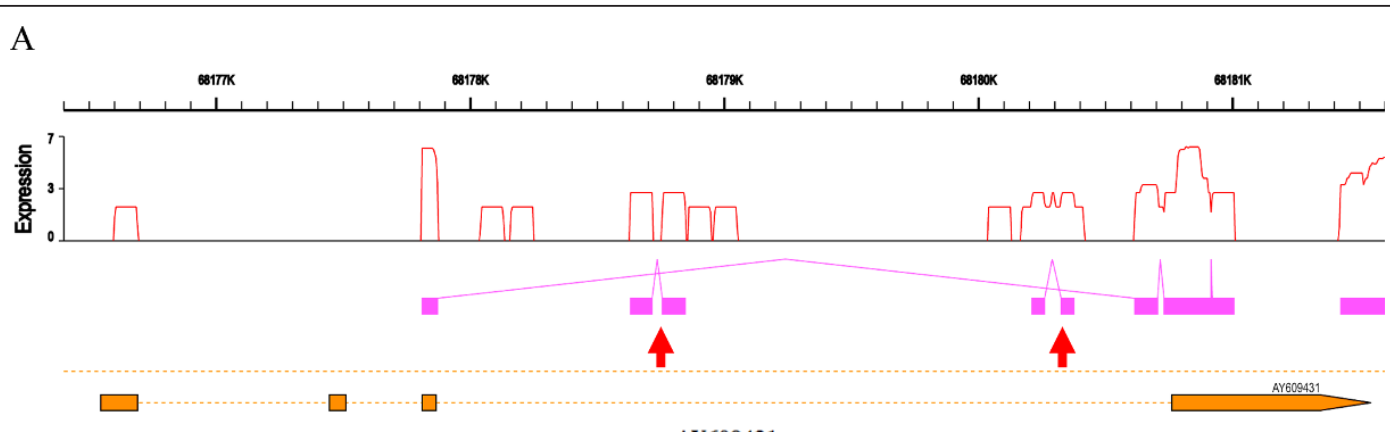

AY609431

B
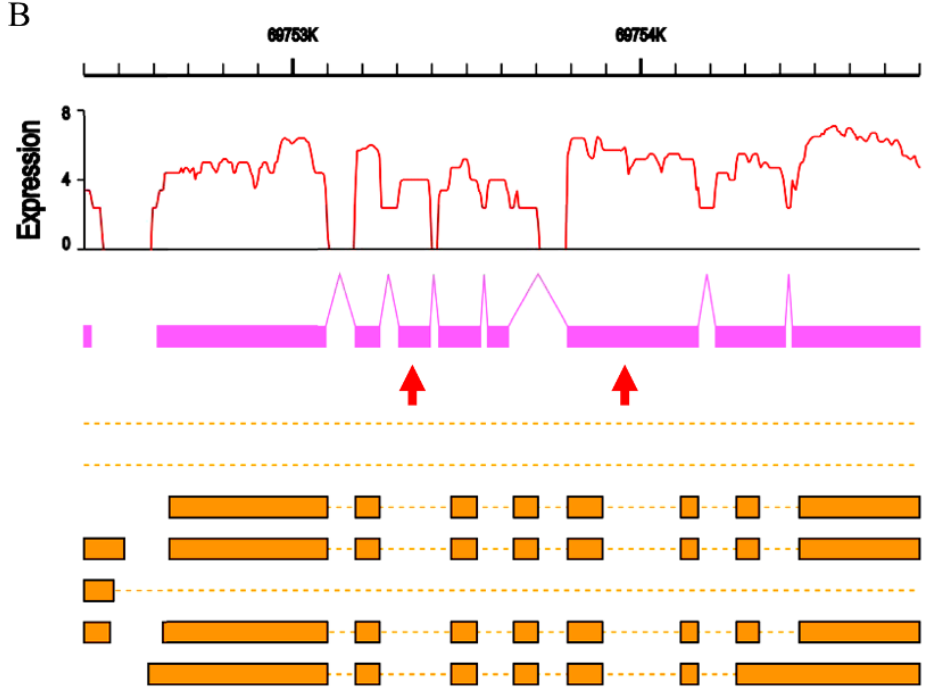

AY609632

$\mathrm{C}$

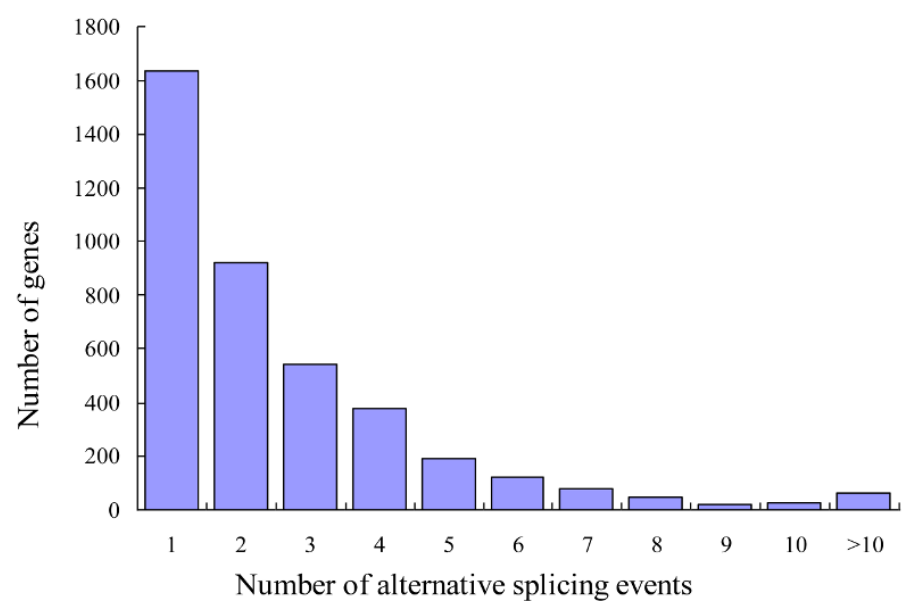

Figure 2 An example of read distributions of genes in reference genome. The schematic diagram depicts the read distributions of AY609431 (A) and AY609632 (B) on pig chromosomes 3 and 2. The red curve shows the expression level (log2 of RPKM) and the pink bar denotes the genomic regions covered by reads in RNA-seq. The yellow bar shows the transcript structures of genes in UCSC. The pink lines highlight the linkage between exons which were supported by at least two distinct junction reads. The red arrows indicate the alternative $5^{\prime}$ splicing in panel $A$ and the retained intron in panel B. The plot (C) shows the distribution of the number of alternative splicing events occurred in each gene and including all four types of alternative splicing models in individual 2268. 
underwent multiple alternative splicing events (Figure $2 \mathrm{C})$, illustrating the complexity of porcine transcriptome. Alternative 3' splicing site is the most common type of alternative splicing events accounting for $40.8 \%$ of all alternative splicing events in pigs, while intron retention and exon-skipping only constituted $7.5 \%$ and $15.6 \%$ in individual 2268 , or $7.4 \%$ and $15.9 \%$ in individual 2270. The average size of retained introns is 536 bp, ranging from $54 \mathrm{bp}$ to $9691 \mathrm{bp}$.

\section{Extension of annotated gene boundaries}

The extensions of 5' and 3' boundaries were determined by comparison of the gene models obtained by RNA-seq with the existing gene annotations. In the six tested samples, a total of 587-815 genes were extended at the 5 ' end, of which more than $65.3 \%$ had an extension of at least $50 \mathrm{bp}$ in length. In comparison, 1,064-1,375 genes were extended at their 3 ' end, of which more than $71.0 \%$ were extended by at least $50 \mathrm{bp}$. Furthermore, 411-672 genes were extended at both ends (Table 1 and Additional file 6). In individual 2268, total 1,399 annotated genes were extended at the 5' end, of which $10.9 \%$ (152) were observed in all three tissues; and 2,505 annotated genes were extended at the 3' end, of which $16.0 \%$ (401) had the extended 3' boundary in all three tissues. Similarly, in individual 2270, the percentage of the extended 5' or 3' genes shared in all three tissues was $10.3 \%$ (147) and $17.0 \%$ (260), respectively.

\section{Comprehensive survey of porcine microRNA by deep sequencing}

To get a comprehensive view of miRNA transcriptome in pigs, we carried out deep sequencing of small RNA (18-30 nt) using the tested samples mentioned above. The obtained miRNA sequence reads have been submitted to the NCBI Gene Expression Omnibus under accession no. GSE26572. We obtained a total of $8,951,703-13,479,372$ raw reads. After removing low quality reads and corrupted adapter sequences, $7,282,608-11,208,822$ clean reads were retained for further analyses. The majority of small RNA was 20-23 nt for all libraries (> 84.0\%), with 22 nt small RNA being the most abundant (Additional file 7), which is in agreement with the common nucleotide length of miRNAs. We mapped $69.2-83.6 \%$ of clean reads to the reference genome (Sscrofa9.2). Chromosomes 1, 2, 3, 6, 12 and 17 harbored clean reads of $>1,000,000$ tags (Figure 3A). After further removal of tRNA, rRNA, scRNA, snRNA, snoRNA, exon RNA, intron RNA and repeat regions, a total of 4,484,788-7,226,415 miRNA sequences were obtained (Additional file 8).

Aligning miRNA sequences to the porcine mature miRNAs in miRBase 15.0 database [27] revealed 86.8 (164/ 189)-94.7 (179/189)\% of mature miRNAs in each sample. We pooled all identified mature miRNAs and found that only five mature miRNAs in miRBase 15.0 database were not detected in this study (Figure 3B). The expression levels of the identified miRNAs displayed a very large range, as reflected by the number of sequence reads, which varied from single counts for rare miRNAs to several hundred thousand reads for the most abundant miRNAs (Additional file 9). As many as $87.3-98.4 \%$ of the clean reads belong to the miRNAs ranked top 20 in expression levels in each sample (Figure 4).

To identify potential novel miRNA, we further analyzed the small RNA tags that could not match known miRNAs and were mapped to intergenic or intronic regions of the reference genome. The characteristic of hairpin structure of miRNA precursor was used to predict novel miRNA by exploring the secondary structure. In total, 26 to 98 potential novel miRNAs each supported by at least five sequence reads, were identified in the 6 tested samples (Figure 3B). The potential novel miRNAs of 6 samples were pooled and the redundancy was removed to get a final set of 164 unique porcine putative novel miRNAs. The vast majorities of these miRNAs were expressed at low levels. Nevertheless, 6 miRNAs showed relatively high expression levels representing by more than 1,000 sequence reads, and 22 by more than 100 sequence reads (Additional file 10).

To determine the genomic locations of these potential novel miRNAs, their precursor sequences were blasted against the porcine reference genome sequence (Sscrofa9.2). As shown in Figure 3C, 94.5\% of the novel miRNAs were assigned to the reference genome. Most of the precursors were located on chromosome $2(\mathrm{n}=$ 20) followed by chromosomes $\times$ and $7(n=17)$, and none of the novel miRNAs were mapped to chromosome 10 .

\section{Cross-tissue comparison of differential transcription events}

Deep RNA sequencing in three types of tissues allows us to investigate the tissue-differentially transcriptional events. Of the 21,414 identified transcripts, 266, 175 and 2,154 transcripts were discovered exclusively in AF, LD and liver, respectively (Figure 1). Interestingly, as reported in humans [14], the majority of alternative splicing events showed clear tissue specificity, demonstrating the importance of alternative splicing in tissue specific programs of gene expression and its major roles in functional complexity. Functional annotations of alternative splicing genes showed that they play important roles in their corresponding tissues. The porcine RYR1 gene (M91451) which had the largest number of LD-specific alternative splicing events has been associated with malignant hyperthermia and has significant 

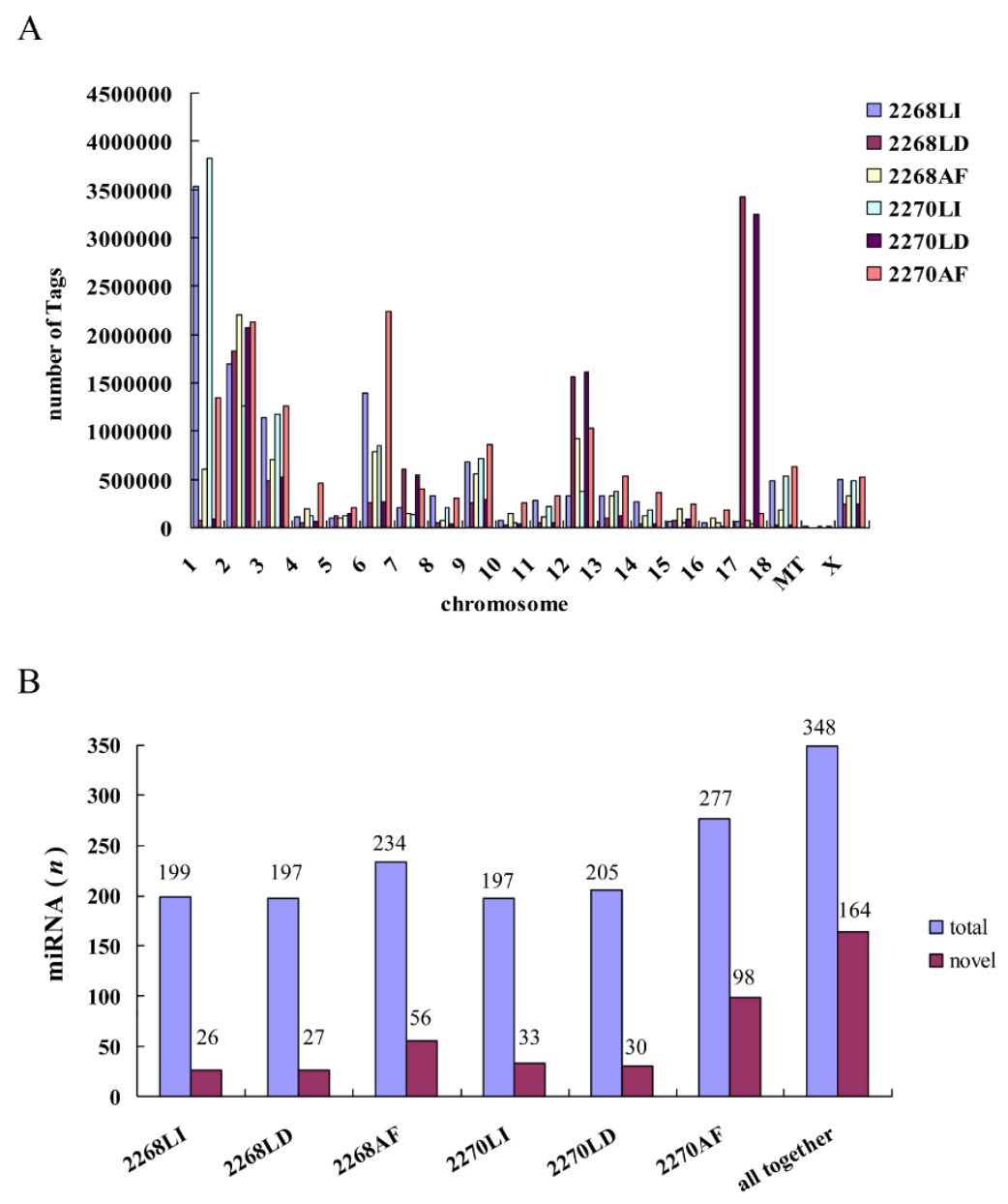

$\mathrm{C}$

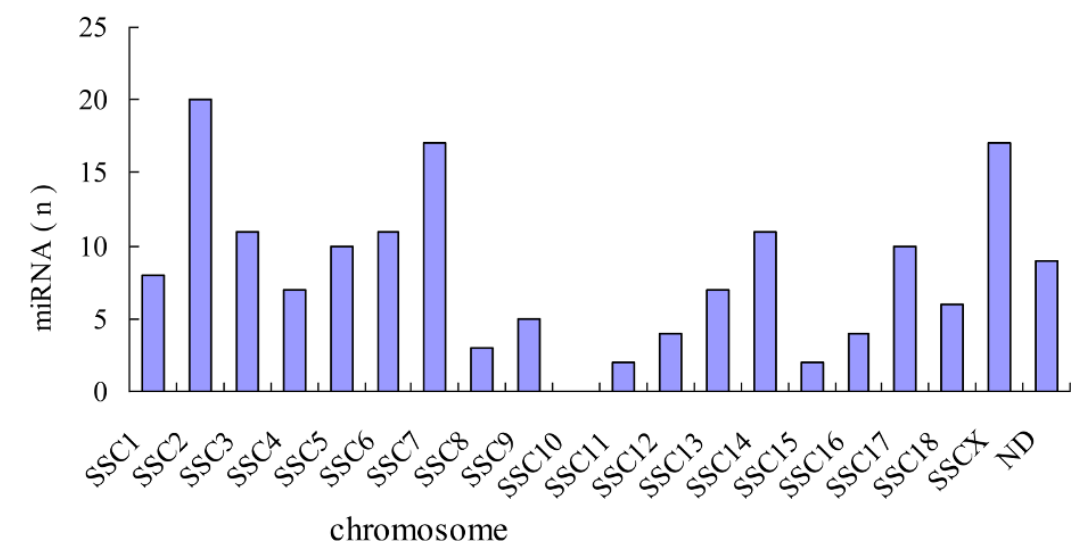

Figure 3 Discovery of miRNAs. (A) The graph shows the abundance of small RNA tags mapped to each chromosome. (B) The number of the identified mature miRNAs and putative novel miRNAs. (C) The number distribution of the putative novel miRNAs mapped to each chromosome. Abbreviation: ND, not determined. 
A

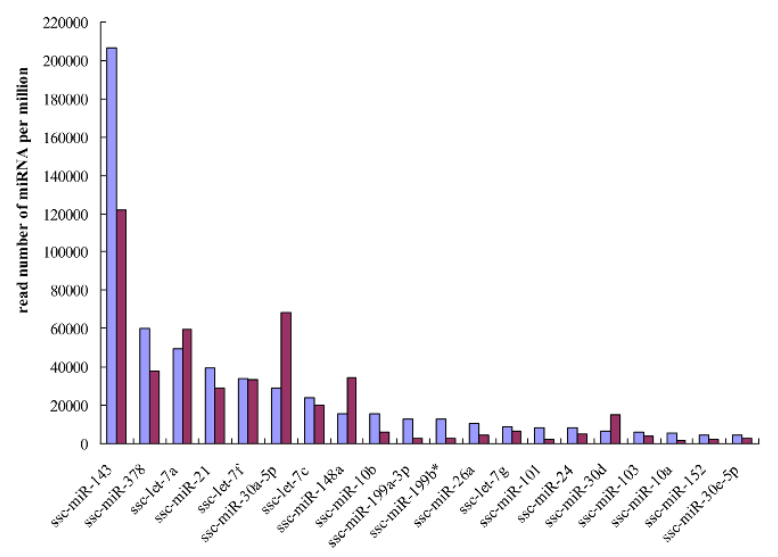

B

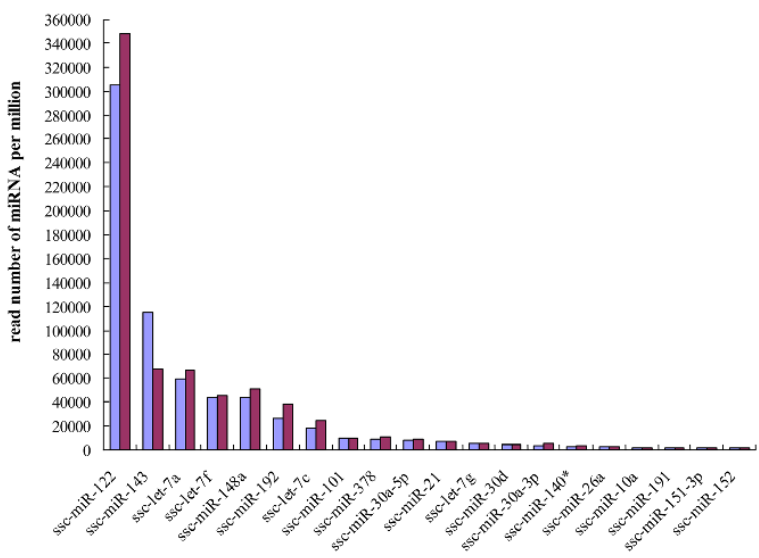

C

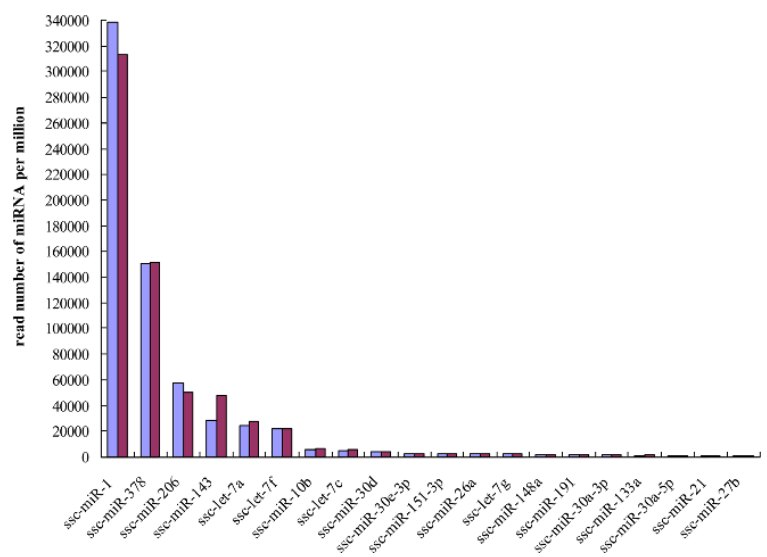

Figure 4 The mature miRNAs ranking top 20 in normalized expression levels in each sample. AF (A), liver (B) and LD muscle (C).

effects on pig meat quality and carcass leanness [28]. The $A L B$ (AK232454) gene having the most number of liver-specific alternative splicing events plays important roles in transportation of fatty acids [29]. SLA-1
(AK231553) implicating in immune and type I diabetes [30] had the most number of alternative splicing events in AF that has been known as an important immune organ. Other tissue-specifically alternative splicing genes 
also show major roles in their corresponding tissues. For instance, $M y H C-2 A$ (AB025260), PPAP2C (FJ436381) and $A P O H$ (AK232456) had tissue-specific alternative splicing in LD, AF and liver, respectively, corresponding to their roles in normal muscle development and function [31], converting phosphatidic acid to diacylglycerol [32], transportation of fatty acids [29], and lipoprotein metabolism [33] (Additional file 11).

The expression abundance of many miRNAs also showed apparently tissue-differential patterns. The mature miRNAs with high abundance in each tissue are conserved in mammals and likely related to important biological functions. MiR-122 is the most abundant miRNA in human liver and also had the most abundance of expressed read counts in porcine liver (Figure 4). MiR-122 plays a crucial role in cholesterol, fatty acid and lipid metabolism [34-36]. The miR-1 and miR-206 are key mediators in proper skeletal and cardiac muscle development and function, myogenesis during embryonic development and muscle cell differentiation [37]. The two miRNAs, respectively, had the most and third abundance of expression level in LD in this study. For those potential novel miRNAs identified in this study, 85 of 164 putative novel miRNAs were specifically identified in AF, 23 and 24 in liver and LD, respectively (Table 2). Their biological functions need further investigation.

\section{Differentially expressed transcripts and miRNAs between two individuals}

Overall, there were clear linear relationships in the gene expression levels $\left(0.84<R^{2}<0.88\right)$ between two individuals in all three tissues. The number of unique reads mapped to different genes ranged from 1 to 894,235. The differentially expressed genes were selected based on the expression profiles and the following criteria: (1) if the fold change in gene expression levels between 2268 and 2270 was more than or equal to two fold ( $\log _{2}$-fold change $\geq 1$ or $\leq-1$ ) and (2) if the false discovery rate value was less than 0.001 . With this, we identified 2,796, 1,551 and 835 differentially expressed genes in $\mathrm{AF}$, liver and $\mathrm{LD}$, respectively. Of these, the

Table 2 The identified putative novel miRNAs

\begin{tabular}{ccccc}
\hline & $\begin{array}{c}\text { Liver- } \\
\text { specific }\end{array}$ & $\begin{array}{c}\text { AF- } \\
\text { specific }\end{array}$ & $\begin{array}{c}\text { LD- } \\
\text { specific }\end{array}$ & $\begin{array}{c}\text { in } \\
\text { total }\end{array}$ \\
\hline 2268-specific & 7 & 17 & 6 & 30 \\
2270-specific & 15 & 52 & 14 & 81 \\
Both in 2268 and 2270 & 1 & 16 & 4 & 21 \\
novel miRNAs identified in more & & & & 28 \\
than one tissues & & & & 4 \\
novel miRnAs identified in all & & & & \\
samples & 23 & 85 & 24 & 164 \\
total number of novel miRNA & & & &
\end{tabular}

expressions of 1,997, 825 and 505 genes were up-regulated in 2268 with respect to individual 2270 (Figure 5A-5C and Additional file 12).

To further investigate the biological relationships of differentially expressed genes with phenotypes, we performed the gene ontology (GO) analysis by querying each differentially expressed gene into the records of the GO database [38]. The results of GO functional annotations are presented in Figure 5D-5F. The main functional groups of differentially expressed genes in AF are related to lipid metabolic process, alcohol metabolic process, lipid binding and protein homooligomerization. The functions of differentially expressed genes in liver are enriched in metabolic process, catalytic activity and oxidoreductase activity. And the differentially expressed genes in LD are mainly associated with metabolic process, cellular metabolic process, catalytic activity and oxidoreductase activity.

Differentially expressed miRNAs between two individuals were identified by comparing the normalized expression data of the mature miRNAs. In total, 10 differentially expressed miRNAs (fold-change $(\log 2) \geq 1$ or fold-change $(\log 2) \leq-1 ; P$-value $<0.01)$ were identified in liver, 20 and 63 in LD and AF, respectively. Most of the differentially expressed miRNAs had relatively low expression levels (Additional file 13). Interestingly, some differentially expressed miRNAs are involved in the pathway relevant to development and diabetes. For instance, miR-214 differentially expressed in LD enables precisely specific the muscle cell types by sharpening cellular responses to Hedgehog in Zebrafish [39]; a liver-differentially expressed miRNA of miR-10b is predicted to regulate genes in pathways relevant to type 2 diabetes [40].

\section{Investigation of candidate genes for related phenotypes by integrated analysis of genome-wide association study (GWAS) and differential gene expression}

We selected total 500 most differentially expressed genes including 200 from liver and AF, respectively, 100 from LD for further functional annotations (if false discover rate of $1 \times 10^{-50}$ was set as the threshold for selecting the transcripts for further analyses, only 100 of 835 differentially expressed genes could be chosen from LD). Only 359 genes could be mapped to the pig reference genome (Sscrofa9.2) and had functional annotations in mammals. Of the 359 genes, 142 have the description of phenotypes in knocked-out mice [41]. A genome-wide association study using the pig 60K SNP chip has been performed in the current White Duroc $x$ Erhualian $\mathrm{F}_{2}$ resource population (unpublished data). Seven, 11 and 4 differentially expressed genes in liver, AF and LD are located within 2.5 Mb around the SNPs that were most significantly associated with phenotypes 


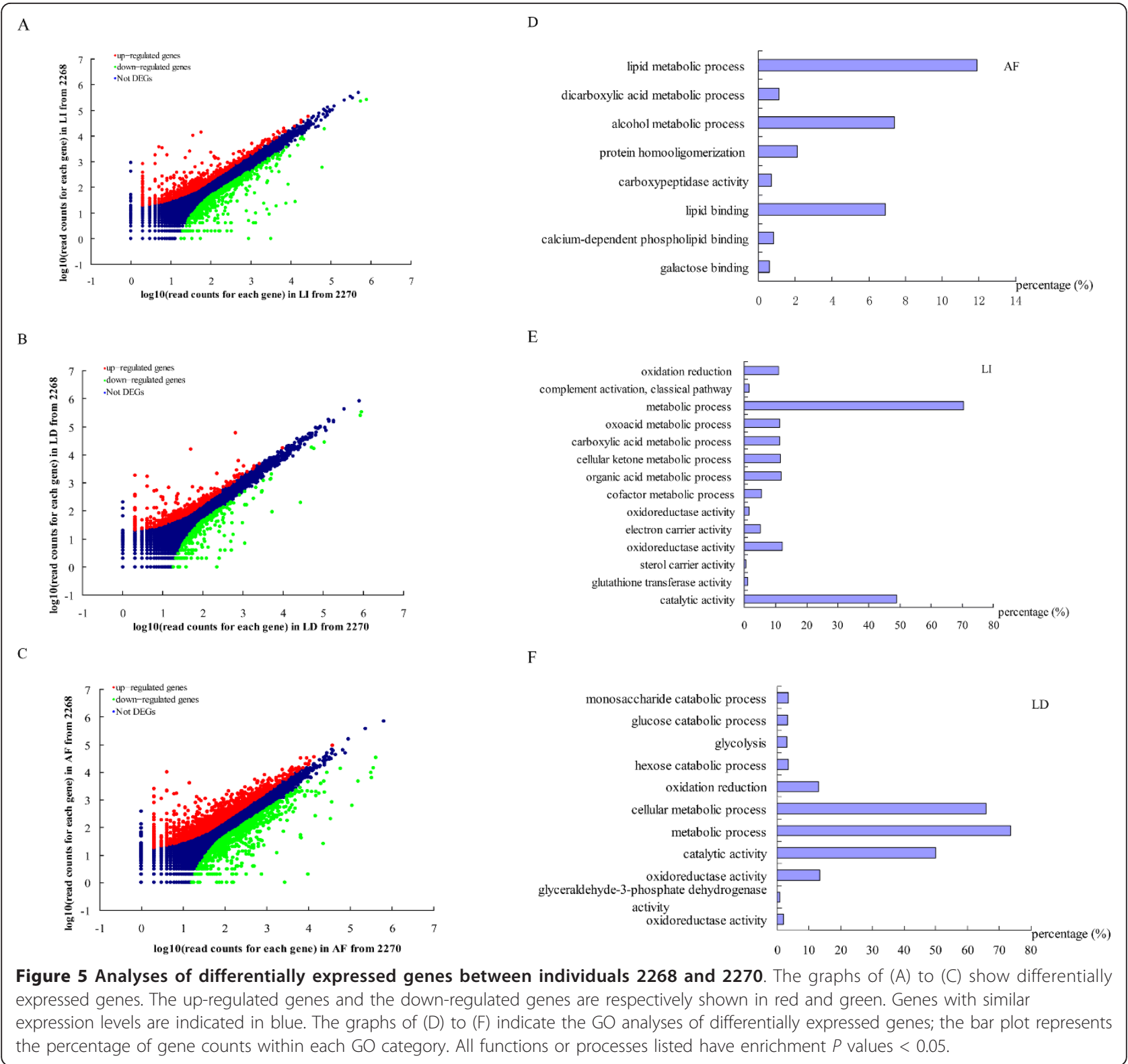

in the GWAS and the associated phenotypes were also observed in the corresponding gene-deficient mice (Additional file 12). Here, we present the identification results of interesting candidate genes IGF2, CYP1A1, $C K M$ and CES1 for the related phenotypes by integrating the analysis of GWAS and differential gene expression in Figure 6.

\section{Confirmation of IGF2 as a causative gene for heart weight} IGF2 is the causative gene underlying the QTL for muscle growth, fat deposition and heart weight on SSC2p [2]. A nucleotide substitution in intron 3 of IGF2 abrogates interaction with ZBED6, resulting in threefold increase of IGF2 messenger RNA expression [42]. In the current $F_{2}$ population, a significant QTL for heart weight at day 240 was located at chr2: $1.3 \mathrm{Mb}$ with a corrected $P$-value of $3.6 \times 10^{-6}$ in GWAS (Figure 6). This region overlapped with the IGF2 locus. In the RNA-seq analysis, individual 2268 with the heavier heart weight (307.5 g vs. $225.0 \mathrm{~g}$ ) showed a 2.3 fold increase in IGF2 expression level compared with individual 2270. The result was perfectly consistent with the previous result [2], and is another example demonstrating the causality of this gene in the QTL.

\section{CYP1A1 as a strong candidate gene for hemoglobin}

Two founder breeds of the $F_{2}$ resource population are White Duroc and Chinese Erhualian, which are 


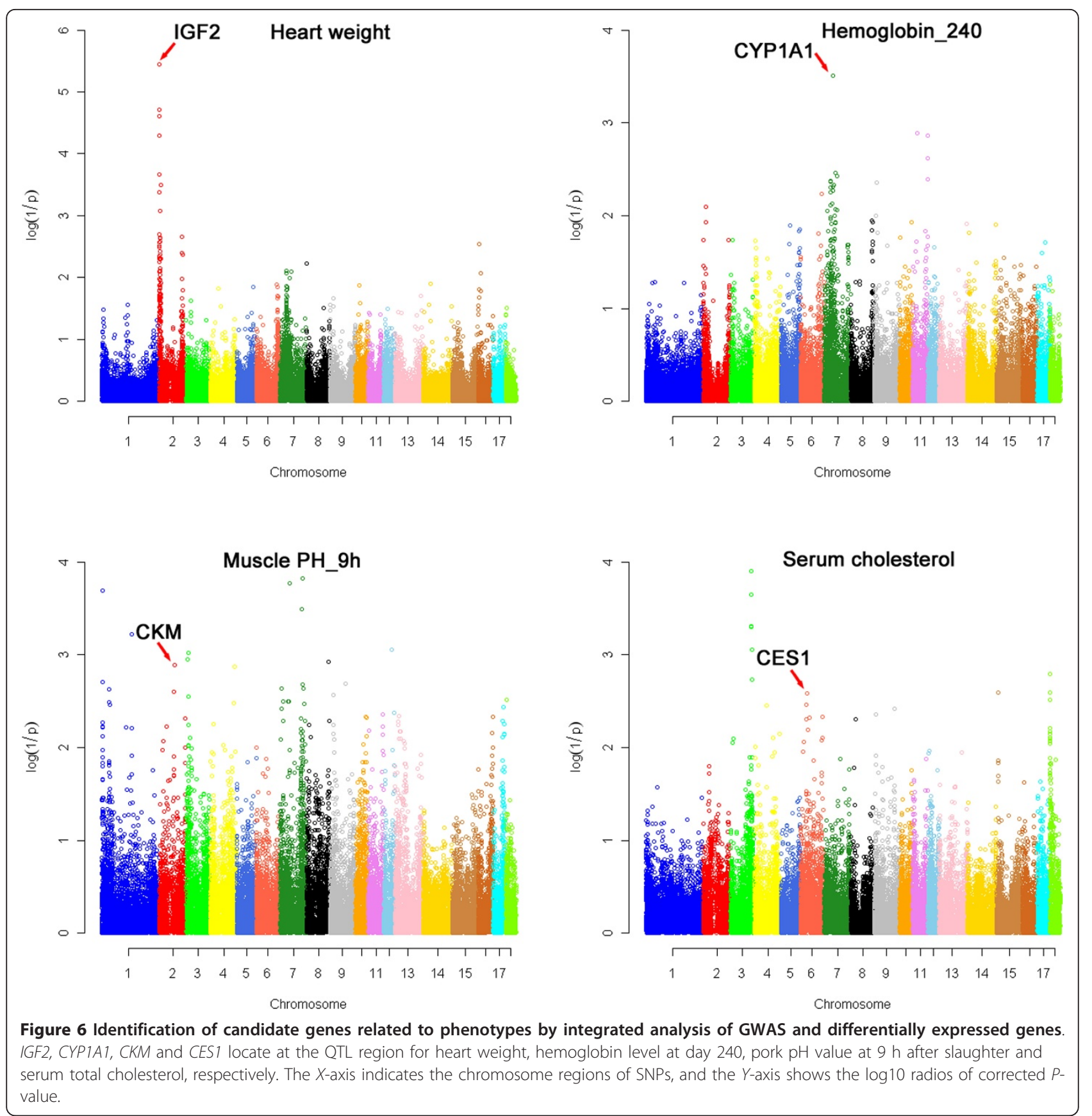

divergent in hemoglobin concentration [43]. Blood parameters of hemoglobin and hematocrit at day 240 were measured in the $F_{2}$ population. We identified a significant QTL for both hemoglobin and hematocrit content at day 240, which is located at chr7: 66.9 Mb in GWAS $\left(P=4.9 \times 10^{-5}\right)$. A differentially expressed gene of CYP1A1 in liver by RNA-seq is located within this QTL region. The CYP1A1 knocked-out mice had the increased hemoglobin content [44]. A quantitative trait transcript (QTT) analysis in this $F_{2}$ population also revealed that the CYP1A1 expression level was associated with hemoglobin at day $240\left(P=2.2 \times 10^{-3}\right.$, unpublished data). These results strongly support CYP1A1 as a candidate for the QTL effect on hemoglobin content.

\section{CKM as a candidate gene for pork $\mathrm{pH}$ value}

Creatine kinase, muscle $(C K M)$ is a cytoplasmic enzyme involved in energy homeostasis. CKM-deficient mice show abnormal muscle physiology and an increased 
skeletal muscle glycogen level [45]. Excess glycogen content in pig skeletal muscle is associated with low meat $\mathrm{pH}$ value, leading to bad meat quality [3]. A significant QTL for meat $\mathrm{pH}$ value at $45 \mathrm{~min}, 3 \mathrm{~h}$ and $9 \mathrm{~h}$ after slaughter was detected around the region of chr2: 80.0 $\mathrm{Mb}$ with a $P$-value of $1.3 \times 10^{-3}$ in the $\mathrm{F}_{2}$ cross. $C K M$ gene locates at the chr2: $79.1 \mathrm{Mb}$ and was differentially expressed in this full-sib pair with different meat $\mathrm{pH}$ values. This indicates that $C K M$ is an important candidate gene for meat $\mathrm{pH}$ value in pigs.

\section{CES1 as an important candidate gene for serum cholesterol and triglyceride level}

The liver is an important organ for lipid metabolism. Gene expression in liver influences the circulating cholesterol level. CES1 that participates in fatty acyl and cholesterol ester metabolism [46] was one of the differentially expressed genes in liver. Our previous QTT study in liver showed that the expression level of CES1 is significantly associated with serum total cholesterol $(P$ $=0.02)$ and triglyceride level $\left(P=7.1 \times 10^{-3}\right)$ in the $F_{2}$ population (Unpublished data). A significant QTL for both low density lipoprotein cholesterol and total cholesterol was identified at chr6: $18.5 \mathrm{Mb}$ containing the CES1 gene in GWAS. The concordant results of QTT, GWAS and differential expression suggest that CES1 is strong candidate gene for QTL affecting serum total cholesterol on chromosome 6 . The supporting evidence was also from the CES1 knocked-out mice that showed decreased circulating cholesterol level [47].

\section{Discussion}

In this study, we presented the systematical transcriptome profiling of pigs on three tissues related to metabolism, meat production and fat deposition using high throughput RNA-seq technology. This efficient deep sequencing not only allows us to analyze novel transcribed regions and miRNAs, but also improves gene annotations at single nucleotide resolution. Integrated analysis of genome-wide association study and differential gene expression between two individuals revealed important candidate genes for related phenotypes.

A total of $38,808,956-40,133,362$ reads were obtained from RNA-seq in six samples with $53.1-60.8 \%$ of reads uniquely mapped to the reference genome. This data set provided comprehensive starting resources for improving the gene annotations across the porcine genome. High $R^{2}$ values between technical replicates showed high reproducibility of RNA-seq in pigs. It should be mentioned that there are still $34.4-38.6 \%$ of reads that cannot be matched to the reference genome. This could be caused by low sequence coverage of the reference genome, reference errors, sequencing errors and defined mapping criterions. A proportion (4.2-8.3\%) of mapped reads with multiple positions was discarded, attributing to known duplicated genes or chromosome segments. A majority of the annotated transcripts $(78.0 \%)$ at UCSC database [24] was covered by sequence reads, showing the sensitivity of RNA-seq in transcript discovery even for lowly expressed genes [48]. Furthermore, we identified large number of novel transcript units which improved the gene annotations of the porcine genome and transcriptome.

Alternative splicing is an important model of gene expression regulation and has not been generally accessible for microarray or SAGE methods in pigs. Some genes showed all four types of alternative splicing models (such as CSN1S1), revealing the complexity of alternative splicing in pigs. We found that alternative 3' splicing is the most common type of alternative splicing events in pigs. This is in contrast to the report in human and yeast where exon-skipping is the most prevalent mechanism $[13,14]$, and it is also different from rice in which intron retention is the primary alternative splicing type [25]. The percentage of alternative 5' or 3' splicing in total alternative splicing events in this study were higher than that reported in Lim et al. (2009) [49] where $8.0 \%$ of alternative 5 ' splicing and $3 \%$ of alternative 3 ' splicing were observed. We discovered that more than $18.0 \%$ of the detected genes were alternatively spliced. This number is much lower than the reported $86.0 \%$ in human [14] and $33.0 \%$ in rice [25]. Three types of alternative splicing models including alternative first exon, alternative last exon and mutually exclusive exon were excluded from analyses because of currently unperfected algorithms. More alternative spliced genes would be discovered if these alternative splicing models were considered.

As an important regulator of gene expression, miRNA regulates the gene expression through decreasing the target mRNA levels or repressing the translation [50,51]. In this study, the high identification rate illustrates that the six small RNA libraries from the tested tissues almost encompass the entire repertoire of known miRNAs. Consistent with the results in Li et al. (2010) [21], porcine mature miRNAs had a broad range of expression levels. The highly expressed miRNAs are known to have important regulatory functions in corresponding tissues. The miR-1/206 showed high abundance of expression levels in muscle (Figure 3C). Interestingly, muscular hypertrophy in Texel sheep has been shown to be caused by a mutation that creates an illegitimate binding site for miR-1/206 in the 3' UTR of the myostatin gene, leading to efficient translational inhibition of the myostatin gene and an increase in muscularity [8]. The miR-122 had the most abundant expression level in liver. It has the diversity of its roles in liver, e.g. metabolism, hepatocarcinogenesis [34]. Just as in humans [52], 
most of the potential novel miRNAs discovered in this study are expressed at low levels (Additional file 10), explaining why they were not discovered in previous efforts and showing the advantage of RNA-seq in transcriptome analysis. Furthermore, we found that most of the novel miRNAs were tissue-specifically identified (Table 2). We cautioned that some could be artifact due to the low expression level, the insufficient depth of sequencing and limited tested tissues.

Mapping genetic factors that underlie quantitative traits in farm animals has been a challenging task [53]. The recent wave of genome-wide association studies in human showed that a majority of SNPs associated with disease traits locate in regulated regions [54]. Integration of gene expression with genotype and phenotype data to elucidate the network of molecular interactions that underlie complex traits can facilitate the identification of variants that contribute to phenotypes [54]. In this study, high-throughput sequencing allowed us to digitally discover an extensive number of differentially expressed genes in the full-sib pair with different phenotypes. Gene ontology analysis indicated that the differentially expressed genes had enrichment on functions related to metabolic process, catalytic activity and lipid binding. The results suggest that these differentially expressed genes are likely related to the phenotypes of growth, metabolism or fat deposition. By integrating GWAS, differentially expressed genes and altered phenotypes in knockedout mice, we found that many differentially expressed genes are the important candidate genes related to the phenotypes of serum cholesterol, growth traits, hemoglobin at day 240 , fatty acid level and muscle $\mathrm{pH}$ value (Additional file 14). For example, activating transcription factor 4 (ATF4) gene differentially expressed in muscle and located in the QTL region for body weight at day 210 is related to decreased body weight in ATF4 knocked-out mice (Table S12) [55]; fatty acid binding protein 4 (FABP4) located in the QTL region for fat deposition on SSC4 and related to increased white adipose tissue amount in FABP4 knocked-out mice was differentially expressed in abdominal fat in this study (Table S12) [56]. The findings provide important clues for further dissecting of the responsible genes and variants.

\section{Conclusions}

This study provides a global view of the complexity of the pig mRNA and miRNA transcriptome, gives an extensive new knowledge about alternative splicing, novel transcript units, gene boundaries and novel miRNAs in pigs. The cross-tissue comparison identified lots of tissue-differential transcription events. Integrated analysis of GWAS and differential gene expression allowed us to detect important candidate genes related to growth, meat quality, serum lipids and fatness. The findings significantly enhance the current genome annotation of pigs and improve our understanding of complex traits.

\section{Methods}

\section{Animals and sample collection}

Two $F_{2}$ full-sib females from a White Duroc $\times$ Erhualian resource population were used in this study. All animals were housed in a consistent and standard environmental condition. The room temperatures were uncontrolled with natural lighting. Animals were floor fed three times a day. The phenotypes of growth (body weight at birth, day 46, 210 and 240), pork $\mathrm{pH}$ value at $45 \mathrm{~min}, 3 \mathrm{~h}, 9 \mathrm{~h}$, $15 \mathrm{~h}$ and $24 \mathrm{~h}$ after slaughter, blood physiological and biochemical parameters including serum cholesterol, hemoglobin and blood cell, carcass traits and meat fatty acid level were measured as described previously [57,58]. The full-sib pair had different phenotypes, such as extremely phenotypic distribution in growth and fatness (Additional file 15). Liver, LD and AF from both individuals were harvested for RNA isolation within 30 mins after slaughter at the age of 240 day. All animal procedures were conducted according to the guidelines for the care and use of experimental animals established by the Ministry of Agriculture of China.

\section{RNA isolation and quality assessment}

Total RNA was isolated with TRIzol (invitrogen) according to the manufacture's instructions. DNA was removed from RNA extracts with RNase-free DNase I (New England Biolabs) for $30 \mathrm{~min}$ at $37^{\circ} \mathrm{C}$. The quality of total RNA was assessed by the 2100 Bioanalyzer (Agilent) and agarose gel electrophoresis.

\section{CDNA library construction and sequencing}

Poly (A) mRNA was isolated from the total RNA samples with oligo (dT) magnetic beads (invitrogen). Purified mRNA was first fragmented by the RNA fragmentation kit (Ambion). The first-strand cDNA synthesis was performed using random hexamer primers and reverse transcriptase (invitrogen), and the second-strand cDNA was synthesized using RNase $\mathrm{H}$ (invitrogen) and DNA polymerase I (New England Biolabs). The cDNA libraries were prepared using the Illumina Genomic DNA Sample Prep kit (Illumina) following the manufacturer's protocol, and then loaded onto flow cell channels of the Illumina Highseq 2000 platform for paired-end $90 \mathrm{bp} \times 2$ sequencing. The average insert size for the paired-end libraries was $200 \mathrm{bp}$ (from 180 to $220 \mathrm{bp}$ ). Total six paired-end cDNA libraries were constructed each for six tested samples (tissues of liver, LD and AF from 
2268 and 2270). One technical replicate was performed for each sample.

\section{Small RNA library preparation and sequencing}

Small RNA libraries were constructed according to the Illumina alternative v1.5 protocol for small RNA sequencing. Briefly, small RNA sized at 18-30 nt was purified from total RNA through polyacrylamide gel electrophoresis, and 3' and 5' Illumina RNA adapters were ligated to the small RNA molecules by T4 RNA ligase (New England Biolabs). The ligated small RNA was subsequently transcribed into cDNA and then amplified for 15 cycles with PCR using primers corresponding to the ends of the adapters. After purified with gel, the amplified cDNA constructs were sequenced according to the Illumina GA platform sequencing protocols.

\section{Mapping reads to the porcine reference genome and annotated transcripts}

The porcine reference genome sequence and annotated transcript set were downloaded from the UCSC (Sscrofa9.2) [24]. After removing reads of low quality (more than half of the base's qualities were less than 5), reads containing Ns $>5$ and reads containing adapters, clean reads were aligned to the porcine reference genome using SOAP2 [59] allowing up to two mismatches in 90 -bp reads. For the reads that were unalignable to the reference sequences, SOAP iteratively trim several base pairs at the 3 '-end and redo the alignment, until a match was detected or the remaining sequence was too short for specific alignment. A similar strategy was used to align reads to the porcine annotated transcript set. The different insert size between paired reads ( 1 bp -10 $\mathrm{kb}$ for mapping to genome, and $<1 \mathrm{~kb}$ for mapping to genes) was set to align the exon-exon junction reads.

\section{Identification of novel transcript units}

All reads that matched to the reference genome with multi-positions were excluded for further analysis. The intergenic regions were defined within the 200-bp down stream of one gene to the 200-bp up stream of the next adjacent gene using the porcine mRNA data (UCSC). A contiguous expression region with each base supported by at least two reads was considered as a transcriptionally active region (TAR). The TARs that were joined by at least one set of paired-end reads were connected into a transcript unit. Those transcript units that were not overlapped with an annotated gene model and located in intergenic regions with a continuous mapping length $\geq 150 \mathrm{bp}$ and average coverage $\geq 2$ were considered as the putative novel transcript units. To determine whether the novel transcript units were non-coding RNAs, we blasted the sequences of the novel transcript units with RNA families in Rfam database (version 10.0) by rfam _ scan.pl (1.0.2) with default threshold [26,60].

\section{Identification of alternative splicing}

To identify potential splicing sites, all putative junction sites which give information about boundaries and combinations of different exons in a transcript were determined by TopHat [61]. All reads that did not match to the genome were aligned onto the splice junctions to identify the junction reads. A junction site was required to be supported by at least two unambiguously mapped reads with non-repetitive match position within the splice and having a minimum of five bases on both sides of the junction.

As described by Wang et al. (2008) [14] and Zhang et al. (2010) [25], and according to the structures of exons, the alternative splicing events were classified into seven different types of alternative splicing models including alternative 3' splice site, alternative 5' splice site, exon skipping, intron retention, alternative first exon, alternative last exon and mutually exclusive exon. The details of these alternative splicing models were described in Zhang et al. (2010) [25]. Because of the unperfected algorithms for alternative first exon, alternative last exon and mutually exclusive exon, only the remaining four alternative splicing models listed above were analyzed and presented in this study.

\section{Determination of gene boundary}

The gene structure was optimized according to the distribution of the reads, paired-end sequences and the annotation of reference genes. After alignment of reads to the reference genome, the genomic regions with continuous reads and uniquely mapped reads $\geq 2$ formed transcription active regions. We connected the different transcription active regions to form a potential gene model using the paired-end data. The extensions of 5' and 3' boundaries were determined by comparison of the potential gene model with the existing gene annotation.

\section{Differentially expressed genes analysis}

Numbers of reads per kilobase of exon region in a gene per million mapped reads were used as the value of normalized gene expression levels [12]. Differentially expressed genes and their corresponding $P$-values were determined with methods described by Audic and Claverie (1997) [62]. The significance threshold of $P$-value in multiple tests was set by false discovery rate (FDR). The fold changes (log2Ratio) were also estimated according to the normalized gene expression level in each sample. We use "FDR $\leq 0.001$ and the absolute value of $\log 2 \mathrm{Ra}$ tio $\geq 1$ " as the threshold to judge the significance of gene expression difference. 


\section{Gene ontology annotation}

The differentially expressed genes were classified for the categories of molecular function, cellular component and biological process using gene ontology (GO) annotation. Hypergeometric test was applied to map all differentially expressed genes to terms in GO database [38] and search significantly enriched GO terms in differentially expressed genes comparing to the genome background. The calculated $P$-values were corrected through bonferroni correction, taking corrected- $P$ value $\leq 0.05$ as a threshold of significance.

\section{Real-time quantitative RT-PCR (qRT-PCR)}

As the current gold standard for quantification of mRNA, to validate the repeatability and reproducibility of gene expression data obtained by RNA sequencing in pigs, we performed qRT-PCR on 16 randomly selected genes including 7 differentially expressed genes with the total RNA used in RNA-seq. The first-strand cDNA was synthesized with superscript II reverse transcriptase (Invitrogen). Gene-specific primers were designed according to the gene sequence using primer premier 5.0 (Additional file 16). The GAPDH gene was used as a control in the experiments. qRT-PCR was carried out in triplicate with Power SYBR Green Mastermix (Applied Biosyetems Inc.) on an Applied Biosystems Step One Plus system using the following program: $95^{\circ} \mathrm{C}$ for 5 min; 35 cycles of $95^{\circ} \mathrm{C}$ for $15 \mathrm{sec}, 60^{\circ} \mathrm{C}$ for $15 \mathrm{sec}$, and $72^{\circ} \mathrm{C}$ for $40 \mathrm{sec} ; 2^{\circ} \mathrm{C}$ for $6 \mathrm{~min}$.

\section{Discovery and annotation of miRNA}

Raw tag sequences were produced by the Illumina Genome Analyzer II at BGI-Shenzhen, China and the data set was analyzed according to the BGI bioinformatics protocols for small RNA. Briefly, the low quality tags and adaptor contaminants formed by adaptor ligation from the 35 nt tags were first filtered from the data set. We then summarized the length distribution of the clean tags and retained only short trimmed reads of sizes from 18 to $30 \mathrm{nt}$.

The distributions of small RNA tags on the reference genome were mapped by SOAP2. Those tags matched with rRNA, scRNA, snoRNA, snRNA and tRNA in Genbank and Rfam database or aligned to exonic and repetitive regions (release 9.0) [26] were excluded from advanced analyses. To determine mature miRNAs, the unique small RNA tags were aligned with the known miRNAs of pigs in miRBase15.0 database [27] with a maximum of two mismatches. For those unannotated small RNA tags that could be mapped to intergenic or intronic regions, Mireap was used to predict potential novel miRNAs by exploring the secondary structure, the dicer cleavage site and the minimum free energy of the precursors [25].
The expressions of miRNAs were normalized to get the expression level of transcripts per million. The differentially expressed miRNAs were determined by calculating the fold-change ( $\log 2$ ratios) and $P$-value from the normalized expression. Fold-change $(\log 2) \geq 1$ or fold-change $(\log 2) \leq-1$ and $P$-value $<0.01$ were used as the thresholds to judge the significance of differentially expressed miRNA.

\section{Integrated analysis of GWAS and differential gene expression}

A panel of $F_{2}$ animals $(n=933)$ was successfully genotyped using Porcine 60K SNP chips (Illumina) and an internally developed SNP set. The genomic position of each SNP (Sscrofa9.2) was determined by SOAP2. The quality control of genotypes was performed with GenABEL procedure in $R$. The associations of the genomewide SNP genotype data with phenotypic traits were analyzed with PLINK, and the significant $P$-values were adjusted by bonferroni correction.

The genomic locations of differentially expressed genes were determined by BLAT [63]. Because of the extensive linkage disequilibrium in $\mathrm{F}_{2}$ crosses, the differentially expressed genes located within $2.5 \mathrm{Mb}$ around the most significant SNPs were selected for further functional annotation. The database in Mouse Genome Informatics [41] was used to search phenotypes linked with differentially expressed genes in knocked-out mice.

\section{Additional material}

Additional file 1: Figure S1 and S2. Repeatability of technical replicates in RNA-seq by comparing the gene expression levels. Figure S1, Scatterplots comparing the gene expression levels (Log10 (read count)) based on technical replicates of LD and $\mathrm{LI}$ from both individuals. Figure S2, Comparison of the expression ratios of randomly selected genes between two individuals obtained by RNA sequencing and QRT-PCR, respectively. The $X$-axis and $Y$-axis show the log 2 radios of gene expression levels of the 2 tested animals determined by qRT-PCR and High-seq 2000, respectively.

Additional file 2: Table S1. Gene expression levels and coverage of transcripts identified in each sample.

Additional file 3: Table S2. Novel transcript units identified in each sample.

Additional file 4: Table S3. Alternative splicing events identified in each sample.

Additional file 5: Table S4. Summary of the number of each type of alternative splicing events in different tissues and individuals.

Additional file 6: Table S5. The detailed description of the extension of gene boundary in each sample.

Additional file 7: Figure S3. The distribution of the nucleotide length of small RNAs. (A) 2268 AF; (B) 2268 Ll; (C) 2268 LD; (D) 2270 AF; (E) 2270 Ll; (F) 2270 LD.

Additional file 8: Table S6. Distribution of the number of small RNA tags among different categories.

Additional file 9: Table S7. The expression levels of the mature miRNAs in each tissue. 
Additional file 10: Table S8. Identification of novel miRNAs and its expression levels in each sample.

Additional file 11: Table S9. Functional annotations of some tissuespecifically alternative splicing genes.

Additional file 12: Table S10. Differentially expressed genes between two individuals in each tissue.

Additional file 13: Table S11. Differentially expressed miRNAs identified in each tissue.

Additional file 14: Table S12. Associations of differentially expressed genes with phenotypes.

Additional file 15: Table S13. The phenotypic values of individuals 2268 and 2270.

Additional file 16: Table S14. Primers for qRT-PCR.

\section{List of Abbreviations}

AF: abdominal fat; ALB: Albumin; APOH: apolipoprotein H; CES1: carboxylesterase 1; CKM: creatine kinase, muscle; CSN1S1: casein alpha-S1; CYP1A1: cytochrome P450, family 1, subfamily A, polypeptide 1; GAPDH: glyceraldehyde-3-phosphate dehydrogenase; IGF2: Insulin-like growth factor 2; LD: longissimus dorsi muscle; MyHC-2A: myosin heavy chain 2a; PPAP2C: phosphatidic acid phosphatase type $2 \mathrm{C}$; RYR1: ryanodine receptor 1; SLA-1: MHC class I antigen 1; ZBED6: zinc finger, BED-type containing 6.

\section{Acknowledgements and funding}

We thank Zujing Han, Zhiyu Peng from BGI Shenzhen, China for their assistances on data analysis. This work was supported by National Natural Science Foundation of China (31160225) and National Basic Research Program of China (2006CB102103).

\section{Authors' contributions}

$\mathrm{LSH}$, conceived and designed the experiments, revised the manuscript; CYC, performed the experiments, analyzed the data, wrote and revised the manuscript; HAS, analyzed the data; JR, provided comments and suggestions for the manuscript; WBL, revised the manuscript; PHL, RMQ, JO and MY, RNA extraction; JWM: genotyped the $F_{2}$ individuals with 60K SNP chip. All authors read and approved the final manuscript.

Received: 26 April 2011 Accepted: 10 September 2011 Published: 10 September 2011

\section{References}

1. Robich MP, Osipov RM, Nezafat R, Feng J, Clements RT, Bianchi C, Boodhwani M, Coady MA, Laham RJ, Sellke FW: Resveratrol improves myocardial perfusion in a swine model of hypercholesterolemia and chronic myocardial ischemia. Circulation 2010, 122:S142-S149.

2. Van Laere AS, Nguyen M, Braunschweig M, Nezer C, Collette C, Moreau L, Archibald AL, Haley CS, Buys N, Tally M, Andersson G, Georges M, Andersson L: A regulatory mutation in IGF2 causes a major QTL effect on muscle growth in the pig. Nature 2003, 425:832-836.

3. Milan D, Jeon JT, Looft C, Amarger V, Robic A, Thelander M, RogelGaillard C, Paul S, lannuccelli N, Rask L, Ronne H, Lundström K, Reinsch N, Gellin J, Kalm E, Roy PL, Chardon P, Andersson L: A mutation in PRKAG3 associated with excess glycogen content in pig skeletal muscle. Science 2000, 288:1248-1251.

4. Mikawa S, Morozumi T, Shimanuki S, Hayashi T, Uenishi H, Domukai M, Okumura N, Awata T: Fine mapping of a swine quantitative trait locus for number of vertebrae and analysis of an orphan nuclear receptor, germ cell nuclear factor (NR6A1). Genome Res 2007, 17:586-593.

5. David L, Huber W, Granovskaia M, Toedling J, Palm CJ, Bofkin L, Jones T, Davis RW, Steinmetz LM: A high-resolution map of transcription in the yeast genome. Proc Natl Acad Sci 2006, 103:5320-5325.

6. Li Q, Lee JA, Black DL: Neuronal regulation of alternative pre-mRNA splicing. Nature Rev Neurosci 2007, 8:819-831.

7. Qureshi IA, Mehler MF: Non-coding RNA networks underlying cognitive disorders across the lifespan. Trends Mol Med 2011, 17:337-346.
8. Clop A, Marcq F, Takeda H, Pirottin D, Tordoir X, Bibé B, Bouix J, Caiment F, Elsen JM, Eychenne F, Larzul C, Laville E, Meish F, Milenkovic D, Tobin J, Charlier C, Georges M: A mutation creating a potential illegitimate microRNA target site in the myostatin gene affects muscularity in sheep. Nat Genet 2006, 38:813-818.

9. Kim TH, Kim NS, Lim D, Lee KT, Oh JH, Park HS, Jang GW, Kim HY, Jeon M, Choi BH, Lee HY, Chung HY, Kim H: Generation and analysis of large-scale expressed sequence tags (ESTs) from a full-length enriched CDNA library of porcine backfat tissue. BMC Genomics 2006, 7:36.

10. Tang Z, Li Y, Wan P, Li X, Zhao S, Liu B, Fan B, Zhu M, Yu M, Li K: LongSAGE analysis of skeletal muscle at three prenatal stages in Tongcheng and Landrace pigs. Genome Biol 2007, 8:R115.

11. Hornshøj H, Conley LN, Hedegaard J, Sørensen P, Panitz F, Bendixen C: Microarray expression profiles of 20000 genes across 23 healthy porcine tissues. PLoS One 2007, 2:e1203.

12. Mortazavi A, Williams BA, McCue K, Schaeffer L, Wold B: Mapping and quantifying mammalian transcriptomes by RNA-seq. Nat Methods 2008, 5:621-628.

13. Sultan M, Schulz MH, Richard H, Magen A, Klingenhoff A, Scherf M, Seifert M, Borodina T, Soldatov A, Parkhomchuk D, Schmidt D, O'Keeffe S, Haas S, Vingron M, Lehrach H, Yaspo ML: A global view of gene activity and alternative splicing by deep sequencing of the human transcriptome. Science 2008, 321:956-960.

14. Wang ET, Sandberg R, Luo S, Khrebtukova I, Zhang L, Mayr C, Kingsmore SF, Schroth GP, Burge CB: Alternative isoform regulation in human tissue transcriptomes. Nature 2008, 456:470-476.

15. Pan Q, Shai O, Lee LJ, Frey BJ, Blencowe BJ: Deep surveying of alternative splicing complexity in the human transcriptome by high-throughput sequencing. Nat Genet 2008, 40:1413-1415.

16. Fullwood MJ, Wei CL, Liu ET, Ruan Y: Next-generation DNA sequencing of paired-end tags (PET) for transcriptome and genome analyses. Genome Res 2009, 19:521-532.

17. McDaneld TG, Smith TP, Doumit ME, Miles JR, Coutinho LL, Sonstegard TS, Matukumalli LK, Nonneman DJ, Wiedmann RT: MicroRNA transcriptome profiles during swine skeletal muscle development. BMC Genomics 2009, 10:77.

18. Xie SS, Huang TH, Shen Y, Li XY, Zhang XX, Zhu MJ, Qin HY, Zhao SH: Identification and characterization of microRNAs from porcine skeletal muscle. Anim Genet 2010, 41:179-190.

19. Huang TH, Zhu MJ, Li XY, Zhao SH: Discovery of porcine microRNAs and profiling from skeletal muscle tissues during development. PLoS One 2008, 3:e3225.

20. Sharbati S, Friedlander MR, Sharbati J, Hoeke L, Chen W, Keller A, Stahler PF, Rajewsky N, Einspanier R: Deciphering the porcine intestinal microRNA transcriptome. BMC Genomics 2010, 11:275.

21. Li M, Xia Y, Gu Y, Zhang K, Lang Q, Chen L, Guan J, Luo Z, Chen H, Li Y, Li Q, Li X, Jiang AA, Shuai S, Wang J, Zhu Q, Zhou X, Gao X, Li X: MicroRNAome of porcine pre- and postnatal development. PLoS One 2010, 5:e11541.

22. Podolska A, Kaczkowski B, Kamp Busk P, Søkilde R, Litman T, Fredholm M, Cirera S: MicroRNA expression profiling of the porcine developing brain. PLoS One 2011, 6:e14494.

23. Nielsen M, Hansen JH, Hedegaard J, Nielsen RO, Panitz F, Bendixen C, Thomsen B: MicroRNA identity and abundance in porcine skeletal muscles determined by deep sequencing. Anim Genet 2010, 41:159-168.

24. UCSC Pig Genome database. [http://genome.ucsc.edu/cgi-bin/hgGateway].

25. Zhang G, Guo G, Hu X, Zhang Y, Li Q, Li R, Zhuang R, Lu Z, He Z, Fang X, Li S, Yang H, Wang J, Wang J: Deep RNA sequencing at single base-pair resolution reveals high complexity of the rice transcriptome. Genome Res 2010, 20:646-654.

26. Rfam database. [http:///fam.sanger.ac.uk].

27. Griffiths-Jones $S$, Saini HK, van Dongen $S$, Enright AJ: miRBase: tools for microRNA genomics. Nucleic Acids Res 2008, 36:D154-D158.

28. Fujii J, Otsu K, Zorzato F, de Leon S, Khanna VK, Weiler JE, O'Brien PJ, MacLennan DH: Identification of a mutation in porcine ryanodine receptor associated with malignant hyperthermia. Science 1991, 253:448-451

29. Baker : Albumin, steroid hormones and the origin of vertebrates. J Endocrinol 2002, 175:121-127.

30. Barrett JC, Clayton DG, Concannon P, Akolkar B, Cooper JD, Erlich HA, Julier C, Morahan G, Nerup J, Nierras C, Plagnol V, Pociot F, Schuilenburg H, 
Smyth DJ, Stevens H, Todd JA, Walker NM, Rich SS, Type 1 Diabetes Genetics Consortium: Genome-wide association study and meta-analysis find that over 40 loci affect risk of type 1 diabetes. Nat Genet 2009, 41:703-707.

31. Tajsharghi H, Hilton-Jones D, Raheem O, Saukkonen AM, Oldfors A, Udd B: Human disease caused by loss of fast lla myosin heavy chain due to recessive MYH2 mutations. Brain 2010, 133:1451-459.

32. Long JS, Pyne NJ, Pyne S: Lipid phosphate phosphatases form homoand hetero-oligomers: catalytic competency, subcellular distribution and function. Biochem J 2008, 411:371-377.

33. Kamboh Ml, Ferrell RE: Apolipoprotein $\mathrm{H}$ polymorphism and its role in lipid metabolism. Adv Lipid Res 1991, 1:9-18.

34. Girard M, Jacquemin E, Munnich A, Lyonnet S, Henrion-Caude A: MiR-122, a paradigm for the role of microRNAs in the liver. J Hepatol 2008, 48:648-656.

35. Krutzfeldt J, Rajewsky N, Braich R, Rajeev KG, Tuschl T, Manoharan M, Stoffel M: Silencing of microRNAs in vivo with 'antagomirs'. Nature 2005 438:685-689.

36. Esau C, Davis S, Murray SF, Yu XX, Pandey SK, Pear M, Watts L, Booten SL, Graham M, McKay R, Subramaniam A, Propp S, Lollo BA, Freier S, Bennett CF, Bhanot S, Monia BP: miR-122 regulation of lipid metabolism revealed by in vivo antisense targeting. Cell Metab 2006, 3:87-98.

37. Taulli R, Bersani F, Foglizzo V, Linari A, Vigna E, Ladanyi M, Tuschl T, Ponzetto C: The muscle-specific microRNA miR-206 blocks human rhabdomyosarcoma growth in xenotransplanted mice by promoting myogenic differentiation. J Clin Invest 2009, 119:2366-2378.

38. GO database. [http://www.geneontology.org/GO.database.shtml].

39. Flynt AS, Li N, Thatcher EJ, Solnica-Krezel L, Patton JG: Zebrafish miR-214 modulates Hedgehog signaling to specify muscle cell fate. Nat Genet 2007, 39:259-263.

40. Herrera BM, Lockstone HE, Taylor JM, Ria M, Barrett A, Collins S, Kaisaki P, Argoud K, Fernandez C, Travers ME, Grew JP, Randall JC, Gloyn AL, Gauguier D, McCarthy MI, Lindgren CM: Global microRNA expression profiles in insulin target tissues in a spontaneous rat model of type 2 diabetes. Diabetologia 2010, 53:1099-1109.

41. Mouse Genome Informatics. [http://www.informatics.jax.org/].

42. Markljung E, Jiang L, Jaffe JD, Mikkelsen TS, Wallerman O, Larhammar M, Zhang X, Wang L, Saenz-Vash V, Gnirke A, Lindroth AM, Barrés R, Yan J, Strömberg S, De S, Pontén F, Lander ES, Carr SA, Zierath JR, Kullander K, Wadelius C, Lindblad-Toh K, Andersson G, Hiälm G, Andersson L: ZBED6, a novel transcription factor derived from a domesticated DNA transposon regulates IGF2 expression and muscle growth. PLOS Biol 2009, 7:e1000256.

43. Johansson A, Pielberg G, Andersson L, Edfors-Lilja I: Polymorphism at the porcine Dominant white/KIT locus influence coat colour and peripheral blood cell measures. Anim Genet 2005, 36:288-296.

44. Dong H, Dalton TP, Miller ML, Chen Y, Uno S, Shi Z, Shertzer HG, Bansal S, Avadhani NG, Nebert DW: Knock-in mouse lines expressing either mitochondrial or microsomal CYP1A1: differing responses to dietary benzo[a]pyrene as proof of principle. Mol Pharmacol 2009, 75:555-567.

45. van Deursen J, Heerschap A, Oerlemans F, Ruitenbeek W, Jap P, ter Laak H, Wieringa B: Skeletal muscles of mice deficient in muscle creatine kinase lack burst activity. Cell 1993, 74:621-631.

46. Zhao B, Song J, Ghosh S: Hepatic overexpression of cholesteryl ester hydrolase enhances cholesterol elimination and in vivo reverse cholesterol transport. J Lipid Res 2008, 49:2212-2217.

47. Wei E, Ben Ali Y, Lyon J, Wang H, Nelson R, Dolinsky WW, Dyck JR, Mitchell G, Korbutt GS, Lehner R: Loss of TGH/Ces3 in mice decreases blood lipids, improves glucose tolerance, and increases energy expenditure. Cell Metab 2010, 11:183-193.

48. Wang $Z$, Gerstein M, Snyder M: RNA-seq: a revolutionary tool for transcriptomics. Nat Rev Genet 2009, 10:57-63.

49. Lim D, Cho YM, Lee KT, Kang Y, Sung S, Nam J, Park EW, Oh SJ, Im SK, Kim H: The Pig Genome Database (PiGenome): an integrated database for pig genome research. Mamm Genome 2009, 1:60-66.

50. Guo H, Ingolia NT, Weissman JS, Bartel DP: Mammalian microRNAs predominantly act to decrease target mRNA levels. Nature 2010, 466:835-840

51. Baek D, Villén J, Shin C, Camargo FD, Gygi SP, Bartel DP: The impact of microRNAs on protein output. Nature 2008, 455:64-71.

52. Creighton CJ, Benham AL, Zhu H, Khan MF, Reid JG, Nagaraja AK, Fountain MD, Dziadek O, Han D, Ma L, Kim J, Hawkins SM, Anderson ML,
Matzuk MM, Gunaratne PH: Discovery of novel microRNAs in female reproductive tract using next generation sequencing. PLoS One 2010, 5 : e9637.

53. Georges M: Mapping, fine-mapping and cloning QTL in domestic animals. Annu Rev Genomics Hum Genet 2007, 8:131-162.

54. Schadt EE: A genome-wide association approach to mapping the genetic determinants of the transcriptome in human populations. Eur J Hum Genet 2006, 14:891-893.

55. Hettmann T, Barton K, Leiden JM: Microphthalmia due to p53-mediated apoptosis of anterior lens epithelial cells in mice lacking the CREB-2 transcription factor. Dev Biol 2000, 222:110-123.

56. Cao H, Maeda K, Gorgun CZ, Kim HJ, Park SY, Shulman Gl, Kim JK, Hotamisligil GS: Regulation of metabolic responses by adipocyte/ macrophage Fatty Acid-binding proteins in leptin-deficient mice. Diabetes 2006, 55:1915-1922.

57. Ren J, Guo YM, Ma JW, Huang LS: Growth and meat quality QTL in pigs with special reference to a very large Erhualian $\times$ White Duroc resource population. Proceedings of the 8th World Congress on Genetics Applied to Livestock Production: 13-18 August, 2006; Belo Horizonte, Minas Gerais, Brazil; 2006, 11-13.

58. Chen R, Ren J, Li W, Huang X, Yan X, Yang B, Zhao Y, Guo Y, Mao H, Huang $L$ : A genome-wide scan for quantitative trait loci affecting serum glucose and lipids in a White Duroc $\times$ Erhualian intercross F2 population. Mamm Genome 2009, 20:386-392.

59. Li R, Yu C, Li Y, Lam TW, Yiu SM, Kristiansen K, Wang J: SOAP2: an improved ultrafast tool for short read alignment. Bioinformatics 2009, 25:1966-1967.

60. Gardner PP, Daub J, Tate JG, Nawrocki EP, Kolbe DL, Lindgreen S, Wilkinson AC, Finn RD, Griffiths-Jones S, Eddy SR, Bateman A: Rfam: updates to the RNA families database. Nucleic Acids Res 2009, 37: D136-D140.

61. Trapnell C, Pachter L, Salzberg SL: TopHat: discovering splice junctions with RNA-seq. Bioinformatics 2009, 25:1105-1111.

62. Audic S, Claverie JM: The significance of digital gene expression profiles. Genome Res 1997, 10:986-995.

63. Blat software. [http://genome.ucsc.edu/cgi-bin/hgBlat].

\section{doi:10.1186/1471-2164-12-448}

Cite this article as: Chen et al.: A global view of porcine transcriptome in three tissues from a full-sib pair with extreme phenotypes in growth and fat deposition by paired-end RNA sequencing. BMC Genomics 2011 12:448.

\section{Submit your next manuscript to BioMed Central and take full advantage of:}

- Convenient online submission

- Thorough peer review

- No space constraints or color figure charges

- Immediate publication on acceptance

- Inclusion in PubMed, CAS, Scopus and Google Scholar

- Research which is freely available for redistribution 